\title{
Aberrant expression of N-glycolyl GM3 ganglioside is associated with the aggressive biological behavior of human sarcomas
}

Daniel Pilco-Janeta ${ }^{1,2,3^{*}+}$ (D), Myriam De la Cruz Puebla ${ }^{10+}$, Jorge Soriano ${ }^{3}$, Marta Osorio ${ }^{4}$, Iraida Caballero ${ }^{3}$, Adanays Calvo Pérez ${ }^{5}$, Laynes Savon ${ }^{6}$, Natalia Cremades ${ }^{7}$, Rancés Blanco ${ }^{8+}$ and Adriana Carr ${ }^{9}$

\begin{abstract}
Background: The aberrant expression of N-glycolyl GM3 ganglioside (NeuGcGM3) in patients with sarcomas was reevaluated by assessing the relation of this molecule with some clinicopathological features and overall survival (OS) of patients.

Methods: Fifty formalin-fixed and paraffin-embedded specimens from patients diagnosed with sarcomas were included. For the evaluation of NeuGcGM3, the 14F7 monoclonal antibody followed by a peroxidase avidin-biotin system was used. Clinicopathological features were obtained from patient records. Survival rates were estimated by the Kaplan-Meier method and compared with the log-rank test. For multivariate analyses, the Cox regression model was used to identify independent prognostic factors for OS.

Results: The majority of samples had high levels of NeuGcGM3 expression (66.0\%) that showed statistical correlation with age $(p=0.014)$, TNM stage $(p=0.022)$, histological grade $(p=0.013)$ and proliferation rates $(p=0.012)$. In addition, a tendency for association with tumor depth $(p=0.070)$ was evidenced. In univariate survival analysis, TNM stage $(p=0.000)$, occurrence of metastasis ( $p=0.000)$ and expression of NeuGcGM3 $(p=0.034)$ were significant prognostic factors for OS, while a tendency for association was evidenced for histological grade $(p=0.091)$. Among these variables, only the presence of metastasis ( $p=0.001$ ) was an independent prognostic factor on multivariate analysis.

Conclusions: The present research suggests the evaluation of NeuGcGM3 expression as a complementary prognostic factor in sarcoma, although our results need to be validated in a larger series and prospective studies. Moreover, our results could support the use of this molecule as a target for immunotherapy.
\end{abstract}

Keywords: Sarcomas, Immunohistochemistry, N-Glycolyl GM3 ganglioside, Clinicopathological parameters, Overall survival

\section{Background}

Soft Tissue Sarcomas (STS) are a heterogeneous group of tumors that originate from primitive mesenchymal tissue, which account for about $1 \%$ of all human malignancies. In spite of advanced gains with multimodality treatments, more than $40 \%$ of cases eventually experience tumor recurrence and metastatic spreading $[1,2]$,

\footnotetext{
*Correspondence: danielpilcojaneta86@gmail.com

†Daniel Pilco-Janeta, Myriam De la Cruz Puebla and Rancés Blanco contributed equally to this work.

'Department of Clinical Oncology, "Teodoro Maldonado Carbo" Hospital, 26 de Julio Avenue, 090203 Guayaquil, Ecuador

${ }^{2}$ Sarcoma Translational Research Laboratory, Vall d'Hebron Institute of

Oncology (VHIO), 08035 Barcelona, Spain

Full list of author information is available at the end of the article
}

which result in a poor overall survival (OS). In this sense, it is of utmost importance to improve our knowledge about the molecular pathogenesis of sarcomas and to develop alternative strategies of treatment against specific molecules. Some of these studies have been focused in total sialic acid content [3] and gangliosides [4].

Gangliosides are sialic acid-containing glycosphingolipids localized in the plasmatic membrane of vertebrate's cell. In normal human tissues, the $\mathrm{N}$-acetylneuraminic acid (NeuAc) is the most common variant of sialic acid, while the presence of $\mathrm{N}$-glycolylneuraminic acid (NeuGc) is limited due to an inactivating mutation in the cytidine

(c) The Author(s). 2019 Open Access This article is distributed under the terms of the Creative Commons Attribution 4.0 International License (http://creativecommons.org/licenses/by/4.0/), which permits unrestricted use, distribution, and reproduction in any medium, provided you give appropriate credit to the original author(s) and the source, provide a link to the Creative Commons license, and indicate if changes were made. The Creative Commons Public Domain Dedication waiver (http://creativecommons.org/publicdomain/zero/1.0/) applies to the data made available in this article, unless otherwise stated. 
monophosphate- $\mathrm{N}$-acetylneuraminic acid hydroxylase (CMP-NeuAc hydroxylase) gene [5]. However, the expression of NeuGc forming part of gangliosides has been found in a variety of human malignancies [6-8], suggesting the potential contribution of these molecules to tumor progression and the metastatic process.

In particular, the aberrant expression of N-glycolyl GM3 ganglioside (NeuGcGM3) was previously reported by immunohistochemistry in a variety of malignant tumors, including pediatric [9] and adult [7, 10] sarcomas. An increased expression of NeuGcGM3 was detected in $59.3-100 \%$ of sarcomas, independently of the histological subtype [9], while the presence of this molecule in normal tissues was scarce $[7,11]$. This fact permitted to consider NeuGcGM3 as an attractive target for both active and passive immunotherapy. However, the role of NeuGcGM3 in the aggressive biological behavior of sarcomas still remains unclear.

In the present study, it was evaluated for the first time, the association of NeuGcGM3 expression with some clinicopathological features of patients with STS. Moreover, the relation of this molecule with the overall survival of patients was assessed.

\section{Methods}

\section{Patients and tissue samples}

A number of 50 formalin-fixed and paraffin-embedded specimens from patients diagnosed with sarcoma, who underwent tumor surgical resection at the "Hermanos Ameijeiras" General Hospital (Havana, Cuba) between 2006 and 2013, were included. Samples from adult patients of any age, sex, race, histological subtype (except GIST) and any stage of disease were included in the study. Samples from patients who were treated or followed up in other medical institution were excluded.

All cases were staged according to the TNM classification established by the American Joint Committee on Cancer (AJCC) [12]. Performance status was evaluated using the ECOG score [13]. Clinical data such as age, gender, tumor size and localization, depth of tumor, the presence of metastasis, disease stage, recurrence, histological subtype and grade of differentiation were obtained from patient records. Overall survival (OS) was measured from the date of surgery to death for any cause or last follow-up and were as calculated for all patients.

This research was conducted after receiving the approved consent by the institutional Ethical Committee.

\section{Monoclonal antibodies}

Sarcomas were immunohistochemically evaluated for a panel including but not limited to vimentin, desmin, panactin, S-100 protein, epithelial membrane antigen (EMA), cytokeratins, HNK-1 (CD57), protein gene product (PGP
9.5), CD99, CD34, c-kit, platelet-derived growth factor receptor (PDGFR), CD68 (MIC2), myogenic regulatory protein (MyoD1), h-caldesmon (HCD), alpha-1 antitrypsin (A1AT), smooth muscle actin (SMA), muscle specific actin (MSA), myoglobin, myogenin, and Ki-67 (MIB-1). For N-glycolyl GM3 ganglioside, the 14F7 Mab (a highly specific IgG1 against this molecule) produced at the Center of Molecular Immunology (Havana, Cuba) was used [11].

\section{Immunohistochemical staining}

The method previously described [7], was used. Briefly, five-micrometer serial sections from each block were obtained, and the slides were dewaxed in xylene and rehydrated in ethanol following standard procedures. Afterward, the samples were incubated with 14F7 Mab followed by a peroxidase avidin-biotin system. Negative controls were performed substituting primary antibody for washing buffer (TBS). As positive controls, sections of breast adenocarcinoma with known positivity for NeuGcGM3 were used. Enzymatic activity was visualized with a DAB solution and slides were counterstained with Mayer's Hematoxylin.

\section{Evaluation of immunostaining}

Immunohistochemical results were analyzed for both proportion of stained cells and intensity of 14F7 Mab reactivity. The percentage of positive cells was graded on a scale of $0-3$ ( 0 , no staining; $1,1-50 \%$; $2,51-75 \%$; and 3 , $76-100 \%)$. The intensity of reaction was graded on a scale of $0-3$; 0 , no staining; 1 , weak staining; 2 , moderate staining; and 3, strong staining. Afterward, an immunoreactive scoring (IRS) was obtained by multiplying the two previously mentioned parameters. Finally, the expression of NeuGcGM3 was divided into low level (IRS $<$ 6) or high level (IRS $\geq 6$ ). For Ki-67 antigen, five areas of greater intensity of staining were subjectively selected and positive and negative cells was counted. Subsequently, the percentage of positive cells (positively stained nuclei/total number of cells $\times 100$ ) was determined and the measure was grouped as follows: low cell proliferation rate $(\leq 10 \%)$, moderate cell proliferation rate $(11-50 \%)$, and high cell proliferation rate $(\geq 50 \%)$. All slides were assessed by two trained observers (LS, NC) who did not have knowledge of clinical characteristics or outcomes.

\section{Statistical analysis}

The relation between NeuGcGM3 expression and clinicopathological variables were analyzed using the chisquare test. Survival rates were estimated by the KaplanMeier method and compared with the log-rank test. For multivariate analyses, the Cox regression model was used to identify independent prognostic factors for OS 
(overall survival). All statistical analyses were performed with the SPSS program (version 21.0; SPSS Inc., Chicago, USA) and GraphPad Prism 6.0 (GraphPad Software, Inc., San Diego, CA). A $p$-value $<0.05$ was considered statistically significant.

\section{Results}

\section{Patient characteristics}

Table 1 shows a summary of clinicopathological features of patients. The median of patient age at presentation was 51 years (ranged from 18 to 82 years). At the time of diagnosis, $19(38.0 \%)$ and $31(62.0 \%)$ of patients presented with 0 and $\geq 1$ ECOG performance status, respectively. Seven of the 50 patients $(14.0 \%)$ showed the presence of metastasis.

Median follow-up for the entire cohort was 2.21 years (range 0.17 to 9.50 ). After 3 -years of follow-up, 22/50 (44.0\%) of patients displayed tumor recurrence and 21/50 $(42.0 \%)$ died within 5 years after diagnosis. According to the first-line therapy used, 37 (74.0\%), 9 (18.0\%) and 4 $(8.0 \%)$ of cases received surgery, chemotherapy and supportive care, respectively. The scheme of chemotherapy used as a neoadjuvant and adjuvant regimen were: Ifosfamide/Doxorubicin, Doxorubicin, Scheme P6, Trabectedin, Gemcitabine/Docetaxel and Ifosfamide/Paclitaxel. Adjuvant radiation therapy was delivered in 19 (38\%) patients.

\section{Expression of N-glycolyl GM3 ganglioside}

The expression of NeuGcGM3 was observed in all cases, although a variable intensity and percentage of positive cells was evidenced (Fig. 1a and b). No alterations in the expression pattern of NeuGcGM3 was evidenced when primary treatment options were compared, as previously described by Blanco et al.. The staining was detected on both the membrane and cytoplasm of tumor cells with a finely granular staining pattern. The majority of samples had strong intensity $(54.0 \%)$ and more than $50 \%$ of positive cells (92.0\%) as shown in Table 2. A strong correlation was found between the percentage of positive tumor cells and staining intensity (Spearman's correlation coefficient $0.564 ; p<0.0001)$. According to the immunoreactive scoring (IRS) $33 / 50(66.0 \%)$ of cases showed high levels of NeuGcGM3 expression.

\section{Survival analysis}

The results of univariate and multivariate survival analysis are summarized in Table 3. In survival analysis, there was a statistically significant difference in the 5year OS rates between high and low expression of NeuGcGM3 (45.4\% vs. $82.3 \%$; $p=0.016$ ), while no significant relation was obtained with Disease-free survival $(p=0.346)$. In addition, univariate analysis showed that
Table 1 Clinicopathological features of studied patients with sarcomas

\begin{tabular}{|c|c|}
\hline Clinicopathological features & No. (\%) \\
\hline \multicolumn{2}{|l|}{ Age (years) } \\
\hline$\leq 60$ & $31(62.0)$ \\
\hline$>60$ & $19(38.0)$ \\
\hline \multicolumn{2}{|l|}{ Gender } \\
\hline Women & $28(56.0)$ \\
\hline Men & $22(44.0)$ \\
\hline \multicolumn{2}{|l|}{ Tumor location } \\
\hline Extremity & $33(66.0)$ \\
\hline Trunk & $11(22.0)$ \\
\hline Head and Neck & $6(12.0)$ \\
\hline \multicolumn{2}{|l|}{ Tumor size (cm) } \\
\hline$<5$ & $13(26.0)$ \\
\hline $5-10$ & $19(38.0)$ \\
\hline$>10$ & $18(36.0)$ \\
\hline \multicolumn{2}{|l|}{ Tumor depth } \\
\hline Superficial & $10(20.0)$ \\
\hline Deep & $40(80.0)$ \\
\hline \multicolumn{2}{|l|}{ TNM Stage } \\
\hline । & $18(36.0)$ \\
\hline$\|$ & $7(14.0)$ \\
\hline III & $18(36.0)$ \\
\hline IV & $7(14.0)$ \\
\hline \multicolumn{2}{|l|}{ Histological subtype } \\
\hline Liposarcoma & $16(32.0)$ \\
\hline Leiomiosarcoma & $8(16.0)$ \\
\hline Pleomorphic/fusocellular & $8(16.0)$ \\
\hline Condrosarcoma & $4(8.0)$ \\
\hline Extraosseous Ewing sarcoma & $4(8.0)$ \\
\hline Other histological subtypes & $10(20.0)$ \\
\hline \multicolumn{2}{|l|}{ Histological grade $(n=47)$} \\
\hline G1 & $15(31.9)$ \\
\hline $\mathrm{G} 2$ & $4(8.5)$ \\
\hline G3 & $28(59.6)$ \\
\hline \multicolumn{2}{|l|}{ Index of cell proliferation } \\
\hline$\leq 10$ & $20(40.0)$ \\
\hline $11-50$ & $21(42.0)$ \\
\hline$>50$ & $9(18.0)$ \\
\hline
\end{tabular}

Legend. TNM Tumor node metastasis

TNM stage $(p=0.000)$, occurrence of metastasis $(p=0.000)$, and expression of NeuGcGM3 $(p=0.034)$ (Fig. 1c) were significant prognostic factors for OS, while a tendency for association was evidenced for a histological grade of tumors $(p=0.091)$. Among these variables, only the presence of metastasis $(\mathrm{HR}=11.34$; 

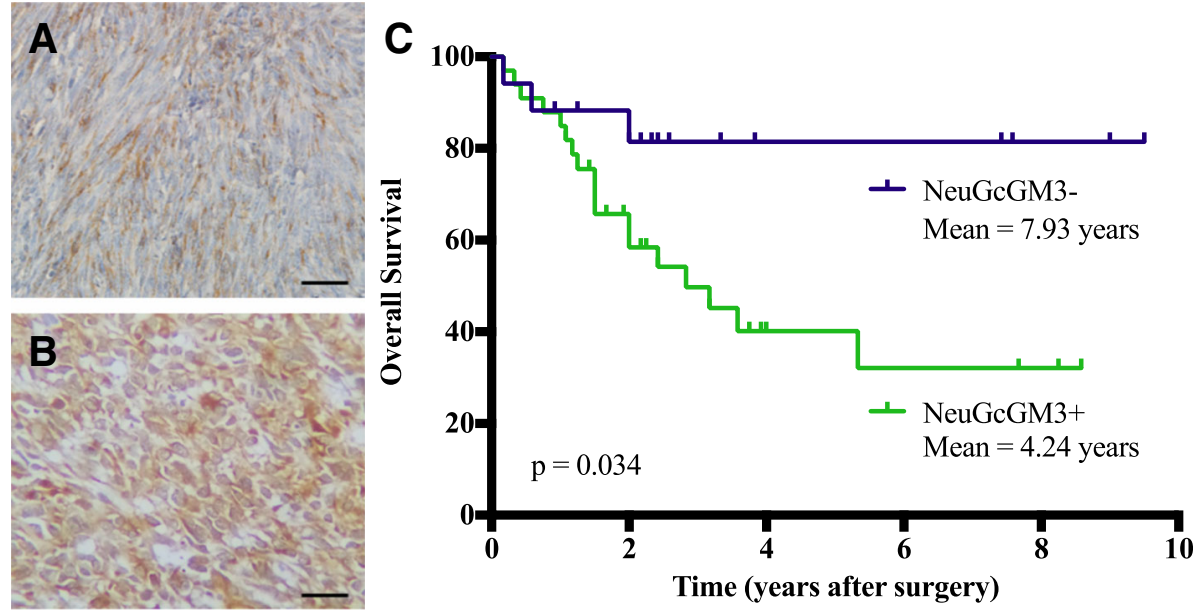

Fig. 1 Expression of NeuGcGM3 in human sarcomas. a and $\mathbf{b}$ : Representative photomicrographs of low (IRS $<6$ ) or high (IRS $\geq 6$ ) NeuGcGM3 expression (brown color), respectively. Counterstaining with Mayer Hematoxylin (blue color). Black bar $=100 \mu$ m. c: Kaplan-Meier survival analyses for overall survival based on NeuGcGM3 expression; NeuGcGM3- (IRS <6) mean = 7.93 years (navy color); NeuGcGM3+ (IRS $\geq 6$ ), mean = 4.24 years (green color). The immunoreactive score (IRS) was used to generate the dichotomous variable

95\% CI 2.60-49.4; $p=0.001)$ was an independent prognostic factor on multivariate analysis.

\section{Relation of NeuGcGM3 expression with clinicopathological features}

The relation of NeuGcGM3 expression with clinicopathological characteristics of patients is shown in Table 4. The level of immunoreactivity (IRS) was associated with age $(p=0.014)$. Interestingly, the presence of this ganglioside was statistically significant increased in advanced clinical stages $(p=0.022)$, high histological grade tumors $(p=0.013)$ as well as in samples displaying an increased index of cell proliferation $(p=0.012)$ (Figs. 2a, $b$ and $c$ ). In addition, the expression of NeuGcGM3 was also increased in deeply located tumors when compared with superficial malignancies. However, only a tendency

Table 2 Expression of NeuGcGM3 ganglioside in sarcomas

\begin{tabular}{ll}
\hline NeuGcGM3 expression & Number (\%) \\
\hline Intensity of reaction & $7(14.0)$ \\
Weak & $16(32.0)$ \\
Moderate & $27(54.0)$ \\
Strong & \\
Percentage of positive cells & $4(8.0)$ \\
$\leq 50$ & $21(42.0)$ \\
$51-75$ & $25(50.0)$ \\
$\geq 76$ & \\
Immunoreactive score (IRS) & $17(34.0)$ \\
Low (IRS < 6) & $33(66.0)$ \\
High (IRS $\geq 6)$ &
\end{tabular}

Legend. NeuGcGM3 N-glycolyl GM3 ganglioside, IRS Immunoreactive score for association was obtained $(p=0.070)$. No significant differences were observed with the rest of the clinicopathological parameters.

\section{Discussion}

Although the presence of NeuGcGM3 has been demonstrated in human tumors of epithelial, neuroectodermal, and mesodermal origins [7], the mechanisms that support its expression still remain unclear. The more accepted hypothesis for the presence of NeuGc in human malignancies is associated with its incorporation from exogenous sources to the altered metabolism of malignant cells $[14,15]$ which is also exacerbate by hypoxia [16]. Along these lines, the expression of NeuGc-containing gangliosides has been shown to be triggered by hypoxic conditions [17]. In particular, Bousquet et al. confirmed the capacity of hypoxia to induce NeuGcGM3 in HeLa cells [18].

In the present study, an increased expression of NeuGcGM3 was detected in $66 \%$ of human sarcomas, regardless of the histological subtype. The presence of this ganglioside was mainly detected in the surface of malignant cells, although diffusion to cytoplasm was also evidenced, as reported by Blanco et al. in these tumors [7]. In previous studies, NeuGc was the predominant sialic acid present on the plasmatic membrane of MG-63 sarcoma cells [19]. Moreover, the expression of cellassociated NeuGc in osteosarcoma cells isolated from patients was demonstrated [20], suggesting the potential role of this molecule in the pathogenesis of osteogenic tumors.

Here, the increased expression of NeuGcGM3 ganglioside was significantly associated with an impaired 5-year 
Table 3 Univariate and multivariate analysis of overall survival in studied population

\begin{tabular}{|c|c|c|c|}
\hline \multirow[t]{2}{*}{ Variables } & \multicolumn{3}{|c|}{$\underline{\text { Overall survival }}$} \\
\hline & $\begin{array}{l}\text { Univariate } \\
p \text { value }\end{array}$ & Multivariate & \\
\hline Age & 0.695 & $\mathrm{HR}(95 \% \mathrm{Cl})$ & $p$ value \\
\hline Gender & 0.615 & & \\
\hline Tumor location & 0.306 & & \\
\hline Performance status & 0.347 & & \\
\hline Tumor size & 0.305 & & \\
\hline Tumor depth & 0.118 & & \\
\hline Occurrence of metastasis & 0.000 & $11.34(2.60-49.4)$ & 0.001 \\
\hline Histological grade & 0.091 & & \\
\hline Index of cell proliferation & 0.757 & & \\
\hline TNM stage & 0.000 & & \\
\hline Recurrence & 0.309 & & \\
\hline NeuGcGM3 expression & 0.034 & & \\
\hline
\end{tabular}

Legend. HR Hazard ratio, Cl Confidence interval, TNM Tumor node metastasis, NeuGcGM3 N-glycolyl GM3 ganglioside. Bold value indicates statistical significance
Table 4 Expression of NeuGcGM3 in relation to selected clinicopathological features

\begin{tabular}{|c|c|c|c|}
\hline \multirow{2}{*}{$\begin{array}{l}\text { Clinicopathological } \\
\text { features }\end{array}$} & \multicolumn{2}{|c|}{ NeuGcGM3 expression (IRS) } & \multirow[t]{2}{*}{$p$ value* $^{*}$} \\
\hline & Low & High & \\
\hline \multicolumn{4}{|l|}{ Age (years) } \\
\hline$\leq 60$ & 15 & 16 & \multirow[t]{2}{*}{0.014} \\
\hline$>60$ & 2 & 17 & \\
\hline \multicolumn{4}{|l|}{ Tumor depth } \\
\hline Superficial & 6 & 4 & \multirow[t]{2}{*}{0.070} \\
\hline Deep & 11 & 29 & \\
\hline \multicolumn{4}{|l|}{ TNM Stage } \\
\hline । & 11 & 7 & \multirow[t]{4}{*}{0.022} \\
\hline$\|$ & 1 & 6 & \\
\hline III & 3 & 15 & \\
\hline IV & 2 & 5 & \\
\hline \multicolumn{4}{|c|}{ Histological grade $(n=47)$} \\
\hline G1 & 10 & 5 & \multirow[t]{3}{*}{0.013} \\
\hline $\mathrm{G} 2$ & 1 & 3 & \\
\hline G3 & 6 & 22 & \\
\hline \multicolumn{4}{|c|}{ Index of cell proliferation } \\
\hline$\leq 10$ & 11 & 9 & \multirow[t]{3}{*}{0.012} \\
\hline $11-50$ & 6 & 15 & \\
\hline$>50$ & 0 & 9 & \\
\hline
\end{tabular}

Legend. NeuGcGM3 N-glycolyl GM3 ganglioside; *Chi-square test, IRS Immunoreactive score, TNM Tumor node metastasis overall survival of patients in the univariate analysis. To the best of our knowledge, this is the first report concerning the potential prognostic role of NeuGcGM3 in human sarcomas. However, in the multivariate analysis only the occurrence of metastasis was an independent factor in predicting clinical outcome. Previously, Lahera et al. published the association of NeuGcGM3 with the reduced overall survival of patients with colon adenocarcinomas [21], while Blanco et al. obtained similar results in NSCLC [22]. In this regard, our results could support the relation of NeuGcGM3 expression with the aggressive biological behavior of sarcomas. Studies regarding the prognostic role of NeuGcGM3 by subtypes of sarcomas with similar clinical behavior are warranted.

The presence of NeuGcGM3 was also related with age of sarcoma patients. In previous research, Kanduma et al. reported an increase in the amount of serum total sialic acid in older patients with sarcomas when compared with the rest of groups. Interestingly, these patients also displayed a reduction in the level of natural anti-NeuGc antibodies [3]. Similar to current research, Lahera et al. obtained a tendency for association between NeuGcGM3 expression and the age of colon adenocarcinoma patients [21]. Furthermore, Rodriguez-Zhurbenko et al. reported a reduction in the production of anti-NeuGcGM3 in older NSCLC patients [23], suggesting the decreased capacity of these patients to effectively fight against tumors. In this sense, the significance of increased expression of NeuGcGM3 in older patients with sarcoma needs further investigation.

In addition, the expression of NeuGcGM3 was significantly increased in high histological grade tumors. In previous studies, Blanco et al. reported a relation of NeuGcGM3 expression with an increased histological grade of both malignant gliomas and transitional cell carcinoma of the urinary bladder [22]. It is recognized that high histological grade sarcomas are characterized by an increase in the proliferation rates [24], occurrence of metastasis, and decreased survival rates [25]. Moreover, the presence of NeuGcGM3 was significantly higher in tumors displaying an increased index of cell proliferation. This result aligns with the results obtained by Blanco et al. in NSCLC using flow cytometry [22] and could support the preferential expression of NeuGcGM3 in more aggressive forms of sarcomas.

Interestingly, the presence of NeuGcGM3 was increased in deep sarcomas when compared with superficial tumors, although only a tendency for statistical association was obtained. It is known that superficial sarcomas are located exclusively above the superficial investing muscular fascia, while deep tumors are defined as either deep or involving the superficial 

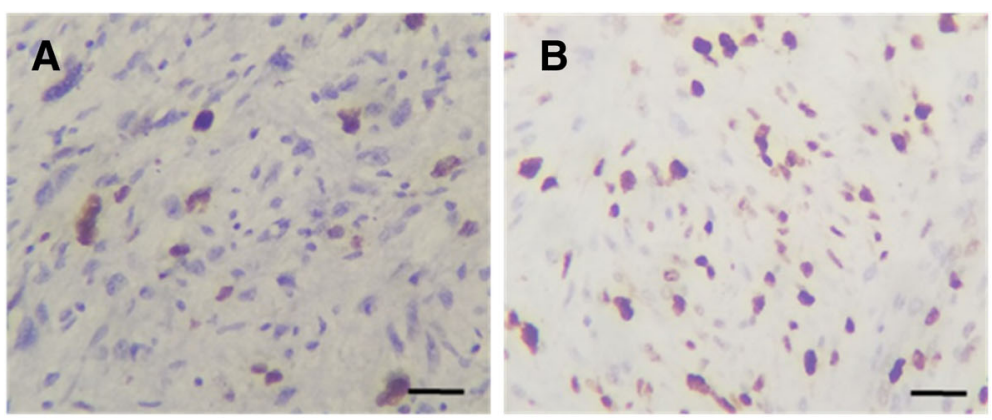

C

NeuGcGM3 expression

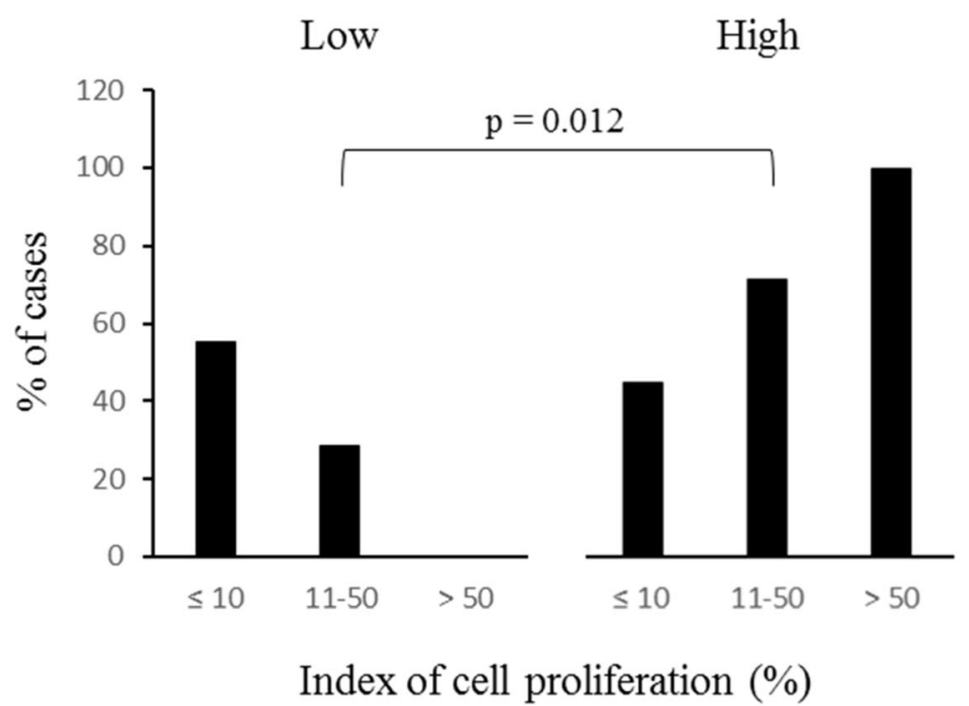

Fig. 2 Index of cell proliferation and NeuGcGM3 expression. a and b: Representative photomicrographs of different levels of nuclear Ki-67 immunostaining (brown color) in sarcomas, as indicative of cell proliferation. Counterstaining with Mayer Hematoxylin (Blue color). Black bar = $100 \mu \mathrm{m}$. c: Distribution of low (IRS <6) or high (IRS $\geq 6$ ) NeuGcGM3 expression according to the index of cell proliferation. Cell proliferation rates was grouped as follow: low ( $\leq 10 \%)$, moderate (11-50\%) and high ( $\geq 50 \%)$

fascia [26]. Consequently, deep sarcomas are usually characterized by an increased local recurrence and metastatic risk $[26,27]$ and also with increased tumor size [28], representing a more aggressive form of the disease.

Finally, the presence of NeuGcGM3 was significantly associated with advanced TNM stage, a clinicopathological feature also related with an adverse clinical outcome of patients. Our data is consistent with a previous report of Lahera et al. regarding colon adenocarcinomas [21]. It is well known that TNM classification is characterized by increased tumor size and the presence of lymph node and/or distant metastasis. However, no relation of NeuGcGM3 expression with tumor size or occurrence of metastasis separately was obtained, resembling other studies in oral melanoma [29], pediatric retinoblastoma [30], and NSCLC [22]. Although our findings suggest the contribution of NeuGcGM3 to tumor growth and progression, further studies in larger series with better distribution by each stage and histological subtype are required.

\section{Conclusions}

In summary, this study reports for the first time the association of NeuGcGM3 expression with the aggressiveness of human sarcomas. The present research suggests the evaluation of NeuGcGM3 expression as a complementary prognostic factor in sarcoma, although our results need to be validated in a larger series and prospective studies. Moreover, our data could support the use of this molecule as a target for immunotherapy. Interestingly, specific therapies against NeuGcGM3 alone or combined with an antiEGFR strategy showed promising clinical benefits in sarcoma patients [31]. Lastly, a Phase I clinical trial using the humanized version of 14F7 Mab in Cuban patients with soft-tissue sarcoma has been started. 


\section{Abbreviations}

AJCC: American Joint Committee on Cancer; ECOG: Eastern Cooperative Oncology Group; EMA: Epithelial membrane antigen; GIST: Gastrointestinal Stromal Tumor; HCD: H-caldesmon; IRS: Immunoreactive scoring; Mab: Monoclonal antibody; MyoD1: Myogenic regulatory protein; NeuAc: Nacetylneuraminic acid; NeuGc: N-glycolylneuraminic acid; NeuGcGM3: Nglycolyl GM3 ganglioside; NSCLC: Non-small-cell lung carcinoma; OS: Overall survival; PDGFR: Platelet-derived growth factor receptor; PGP: Protein gene product; SMA: Smooth muscle actin; STS: Soft Tissue Sarcomas; TBS: Trisbuffered saline; TNM: Tumor, nodule and metastasis

\section{Acknowledgments}

The authors want to express gratitude to Professor Cindy Weinstein from the University of California-San Francisco for helpful editorial assistance.

\section{Authors' contributions}

DPJ, JS, IC and MO conceived the project. DPJ and RB wrote the manuscript. $M D, A C P, L S, N C$ and $A C$ made a substantial contribution to the discussion of content. All authors have read and approved the manuscript.

\section{Funding}

The financial support was provided by the National Secretary of Higher Education, Science, Technology and Innovation (SENESCYT Quito-Ecuator) with a Postgraduate Research Scholarship to DPJ, "Hermanos Ameijeiras" Clinical and Surgical Hospital (Havana, Cuba) and the National Institute of Oncology and Radiobiology (Havana, Cuba) support with the research costs associated with this study.

\section{Availability of data and materials}

The data used to support the findings of this study are available from the corresponding author upon request.

\section{Ethics approval and consent to participate}

This study was approved by the Institutional Review Board of "Hermanos Ameijeiras" Clinical and Surgical Hospital. All procedures performed in studies involving human participants were in accordance with the ethical standards of the institutional research committee and with the $1964 \mathrm{Helsinki}$ Declaration and its later amendments or comparable ethical standards.

\section{Consent for publication}

Not applicable.

\section{Competing interests}

The authors declared no potential competing interests.

\section{Author details}

1Department of Clinical Oncology, "Teodoro Maldonado Carbo" Hospital, 26 de Julio Avenue, 090203 Guayaquil, Ecuador. ${ }^{2}$ Sarcoma Translational Research Laboratory, Vall d'Hebron Institute of Oncology (VHIO), 08035 Barcelona, Spain. ${ }^{3}$ Department of Clinical Oncology, "Hermanos Ameijeiras" Clinical and Surgical Hospital, San Lázaro Street № 701 and Belascoaín, 10400 Havana, Cuba. ${ }^{4}$ Clinical Trials Unit, National Institute of Oncology and Radiobiology, 29 and F Street Vedado, 10400 Havana, Cuba. ${ }^{5}$ Department of Cell Biology and Tissues Banking, National Institute of Oncology and Radiobiology, 29 and F Street Vedado, 10400 Havana, Cuba. ${ }^{6}$ Department of Anatomic Pathology, "Hermanos Ameijeiras" Clinical and Surgical Hospital, San Lázaro Street N 701 and Belascoaín, 10400 Havana, Cuba. ${ }^{7}$ Department of Anatomic Pathology, "Teodoro Maldonado Carbo" Hospital, 26 de Julio Avenue, 090203 Guayaquil, Ecuador. ${ }^{8}$ Laboratory of Recognition and Biological Activity Assays, 216 Street and 15 Avenue, Atabey, Playa, P.O. Box 16040, 11600 Havana, Cuba. ${ }^{9}$ Research and Development Direction, 216 Street and 15 Avenue, Atabey, Playa, P.O. Box 16040, 11600 Havana, Cuba. ${ }^{10}$ Atlantic Fellows for Equity in Brain Health, University of California, San Francisco (UCSF), Nelson Rising Lane, Suite 190, San Francisco, CA 94143, USA.

\section{Received: 24 March 2019 Accepted: 23 May 2019} Published online: 10 June 2019

\section{References}

1. Judson I, Verweij J, Gelderblom H, Hartmann JT, Schöffski P, Blay J-Y, et al. Doxorubicin alone versus intensified doxorubicin plus ifosfamide for first- line treatment of advanced or metastatic soft-tissue sarcoma: a randomised controlled phase 3 trial. Lancet Oncol. 2014 Apr;15(4):415-23.

2. Frezza AM, Stacchiotti S, Gronchi A. Systemic treatment in advanced soft tissue sarcoma: what is standard, what is new. BMC Med [Internet]. 2017; 15(1) Available from: http://bmcmedicine.biomedcentral.com/articles/10. 1186/s12916-017-0872-y.

3. Kanduma EG, Mukuria JC, Mwanda OW. Serum total sialic acid and Hanganutziu-Deicher antibody in normals and in cancer patients. East Afr Med J. 2007 May;84(5):207-14.

4. Roth M, Linkowski M, Tarim J, Piperdi S, Sowers R, Geller D, et al. Ganglioside GD2 as a therapeutic target for antibody-mediated therapy in patients with osteosarcoma: GD2 as a target in osteosarcoma. Cancer. 2014; 120(4):548-54.

5. Irie A, Suzuki A. CMP-N-Acetylneuraminic acid hydroxylase is exclusively inactive in humans. Biochem Biophys Res Commun. 1998 Jul;248(2):330-3.

6. Hayashi N, Chiba H, Kuronuma K, Go S, Hasegawa Y, Takahashi M, et al. Detection of $\mathrm{N}$-glycolyated gangliosides in non-small-cell lung cancer using GMR8 monoclonal antibody. Cancer Sci. 2013 Jan;104(1):43-7.

7. Blanco R, Quintana Y, Blanco D, Cedeño M, Rengifo CE, Frómeta M, et al. Tissue reactivity of the $14 \mathrm{~F} 7$ Mab raised against N-Glycolyl GM3 ganglioside in tumors of Neuroectodermal, mesodermal, and epithelial origin. J Biomark. 2013;2013:1-9.

8. Palomo AG, Santana RB, Perez XE, Santana DB, Gabri MR, Monzon KL, et al. Frequent co-expression of EGFR and NeuGcGM3 ganglioside in cancer: it's potential therapeutic implications. Clin Exp Metastasis. 2016 Oct;33(7):717-25.

9. Scursoni AM, Galluzzo L, Camarero S, Pozzo N, Gabri MR, de Acosta CM, et al. Detection and characterization of N-Glycolyated gangliosides in Wilms tumor by immunohistochemistry. Pediatr Dev Pathol. 2010;13(1):18-23.

10. Blanco R. Double Expression of Epidermal Growth Factor Receptor and NGlycolyl GM3 Ganglioside in Human Malignant Tumors. A Study in Four Different Clinical Scenarios. 2017;2(1):6.

11. Carr A, Mullet A, Mazorra Z, Vázquez AM, Alfonso M, Mesa C, et al. A mouse lgG , monoclonal antibody specific for $N$-Glycolyl GM3 ganglioside recognized breast and melanoma tumors. Hybridoma. 2000 Jun;19(3):241-7.

12. Edge SB, Compton CC. The American joint committee on Cancer: the 7th edition of the AJCC Cancer staging manual and the future of TNM. Ann Surg Oncol. 2010 Jun;17(6):1471-4.

13. Oken MM, Creech RH, Tormey DC, Horton J, Davis TE, McFadden ET, et al. Toxicity and response criteria of the eastern cooperative oncology group. Am J Clin Oncol. 1982 Dec;5(6):649-55.

14. Ecsedy JA, Holthaus KA, Yohe HC, Seyfried TN. Expression of mouse sialic acid on gangliosides of a human glioma grown as a xenograft in SCID mice. J Neurochem. 1999 Jul;73(1):254-9.

15. Tangvoranuntakul P, Gagneux P, Diaz S, Bardor M, Varki N, Varki A, et al. Human uptake and incorporation of an immunogenic nonhuman dietary sialic acid. Proc Natl Acad Sci. 2003;100(21):12045.

16. Yin J, Hashimoto A, Izawa M, Miyazaki K, Chen G-Y, Takematsu H, et al. Hypoxic culture induces expression of Sialin, a sialic acid transporter, and Cancer-associated gangliosides containing non-human sialic acid on human Cancer cells. Cancer Res. 2006 Mar 15;66(6):2937-45.

17. Alisson-Silva F, Kawanishi K, Varki A. Human risk of diseases associated with red meat intake: analysis of current theories and proposed role for metabolic incorporation of a non-human sialic acid. Mol Asp Med. 2016 Oct; 51:16-30.

18. Bousquet PA, Sandvik JA, Jeppesen Edin NF, Krengel U. Hypothesis: hypoxia induces de novo synthesis of NeuGc gangliosides in humans through CMAH domain substitute. Biochem Biophys Res Commun. 2018 Jan;495(1):1562-6.

19. Tzanakakis GN, Nikitovic D, Katonis P, Kanakis I, Karamanos NK. Expression and distribution ofN-acetyl andN-glycolylneuraminic acids in secreted and cell-associated glycoconjugates by two human osteosarcoma cell lines. Biomed Chromatogr. 2007 Apr;21(4):406-9.

20. Phitak T, Klangjorhor J, Pothacharoen P, Pruksakorn D, Kongtawelert P. Level and distribution of secreted and cell-associated N-acetyl, Nglycolylneuraminic, and deaminoneuraminic acids in osteosarcoma cells isolated from patients. ScienceAsia. 2017:43(1):15.

21. Lahera T, Calvo A, Torres G, Rengifo CE, Quintero S, Arango M del C, et al. Prognostic role of $14 \mathrm{~F} 7$ Mab immunoreactivity against N-Glycolyl GM3 ganglioside in Colon Cancer. J Oncol. 2014;2014:1-8.

22. Blanco R, Domínguez E, Morales O, Blanco D, Martínez D, Rengifo CE, et al. Prognostic significance of N-Glycolyl GM3 ganglioside expression in non- 
small cell lung carcinoma patients: new evidences. Pathol Res Int. 2015 Nov 8;2015:1-12.

23. Rodríguez-Zhurbenko N, Martínez D, Blanco R, Rondón T, Griñán T, Hernández AM. Human antibodies reactive to NeuGcGM3 ganglioside have cytotoxic antitumor properties: clinical immunology. Eur J Immunol. 2013; 43(3):826-37.

24. Samta Shakya SG. Typing and grading of soft tissue tumors and their correlation with proliferative marker Ki-67. J Cytol Histol. 2015;06(03).

25. Coindre J-M. Grading of soft tissue sarcomas: review and update. Arch Pathol Lab Med. 2006;130:6.

26. Kotilingam D, Lev DC, Lazar AJF, Pollock RE. Staging soft tissue sarcoma: evolution and change. CA Cancer J Clin. 2006 Sep 1;56(5):282-91.

27. Salas S, Stoeckle E, Collin F, Bui B, Terrier P, Guillou L, et al. Superficial soft tissue sarcomas (S-STS): a study of 367 patients from the French sarcoma group (FSG) database. Eur J Cancer. 2009 Aug:45(12):2091-102.

28. Rydholm A, Gustafson P. Should tumor depth be included in prognostication of soft tissue sarcoma? BMC Cancer [Internet] 2003 Dec [cited 2019 Jan 12];3(1). Available from: http://bmccancer.biomedcentral. com/articles/10.1186/1471-2407-3-17.

29. Zhong Y, Wu Y, Li C, Tang J, Wang X, Ren G, et al. N-Glycolyl GM3 ganglioside immunoexpression in oral mucosal melanomas of Chinese: the 14F7 MAb imunorecognition in oral mucosal melanomas. Oral Dis. 2012; 18(8):741-7.

30. Torbidoni AV, Scursoni A, Camarero S, Segatori V, Gabri M, Alonso D, et al. Immunoreactivity of the 14F7 Mab raised against N-Glycolyl GM3 ganglioside in retinoblastoma tumours. Acta Ophthalmol. 2015;93(4): e294-300

31. Palomo AG, Medinilla AL, Segatori V, Barroso MDC, Blanco R, Gabri MR, et al. Synergistic potentiation of the anti-metastatic effect of anti EGFR mAb by its combination with immunotherapies targeting the ganglioside NGcGM3. Oncotarget. 2018;9(35):24069-80.

\section{Publisher's Note}

Springer Nature remains neutral with regard to jurisdictional claims in published maps and institutional affiliations.

Ready to submit your research? Choose BMC and benefit from:

- fast, convenient online submission

- thorough peer review by experienced researchers in your field

- rapid publication on acceptance

- support for research data, including large and complex data types

- gold Open Access which fosters wider collaboration and increased citations

- maximum visibility for your research: over $100 \mathrm{M}$ website views per year

At $\mathrm{BMC}$, research is always in progress.

Learn more biomedcentral.com/submissions 